\title{
STEROIDOGENESIS IN OVARIAN TISSUE OF A VIVIPAROUS TELEOST, THE GUPPY POECILIA RETICULATA
}

\author{
J. G. D. Lambert and M. G. E. Pot \\ Zoological Laboratory, Section for Comparative Endocrinology, State University of Utrecht, Utrecht, \\ The Netherlands
}

(Received 8 April 1974)

\begin{abstract}
Homogenates of ovaries of 3- and 12-month-old guppies were incubated with pregnenolone-7 $\alpha-{ }_{-8}^{8} \mathrm{H}$ and progesterone-4- ${ }^{14} \mathrm{C}$, and with androstenedione-1,2- ${ }^{3} \mathrm{H}$, respectively.

2. From the double-labeled experiment, 17 $\alpha$-hydroxypregnenolone, 17 $\alpha$-hydroxyprogesterone, dehydroepiandrosterone, androstenedione and testosterone were isolated and identified by paperand thin-layer chromatography, derivative formation and by recrystallization to constant specific activity.

3. In the ovary of the guppy the delta-5 pathway in steroidogenesis predominates, as may be concluded from the ${ }^{3} \mathrm{H} /{ }^{14} \mathrm{C}$ ratios of the identified metabolites.

4. From the androstenedione-1,2- ${ }^{3} \mathrm{H}$ incubation, ovaries of 12 -month-old guppies appeared to be able to synthesize steroids with functional groups in the 11-position (11-ketotestosterone and 11 $\beta$ hydroxytestosterone).

5. The androgen synthesis in ovaries of older guppies may be considered as a possible explanation of the sex conversion occasionally observed.
\end{abstract}

\section{INTRODUCTION}

IN PREvious studies (Lambert et al., 1971), it was shown that the ovary of the viviparous teleost Poecilia reticulata contains aromatizing enzymes, which are able to catalyse the conversions of androstenedione* and testosterone to oestradiol. However, direct evidence for complete steroid synthesis in the ovary of this teleost was not obtained. An incubation experiment with the radioactive precursors ${ }^{8} \mathrm{H}$-pregnenolone and ${ }^{14} \mathrm{C}$-progesterone was considered necessary. Such a double-labeled experiment could also be used to discriminate between a delta -4 and a delta- 5 pathway in steroid synthesis.

* The following trivial names are used throughout this paper: progesterone, pregn-4-ene-3,20-dione; pregnenolone, $3 \beta$-hydroxypregn-5-ene-20-one; $17 \alpha$-hydroxyprogesterone, $17 \alpha$-hydroxypregn-4-ene-3,20-dione; $17 \alpha$ -

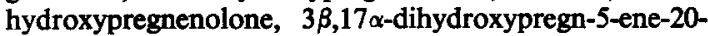
one; dehydroepiandrosterone, $3 \beta$-hydroxyandrost-5-ene17-one; androstenedione, androst-4-ene-3,17-dione; testosterone, 17 $\beta$-hydroxyandrost-4-ene-3-one; adrenosterone, androst-4-ene-3,11,17-trione; $11 \beta$-hydroxyandrostenedione, $\quad 11 \beta$-hydroxyandrost-4-ene-3,17dione; 11-ketotestosterone, 17 $\beta$-hydroxyandrost-4-ene3,11-dione; 11 $\beta$-hydroxytestosterone, $11 \beta, 17 \beta$-dihydroxyandrost-4-ene-3-one; cortisol, 11 $\beta, 17 \alpha, 21$-trihydroxypregn-4-ene-3,20-dione; cortisone, 17a,21-dihydroxypregn-4-ene-3,11,20-trione; oestradiol, 3,17 $\beta$-dihydroxyoestra-1,3,5(10)-triene; oestrone, 3-hydroxyoestra1,3,5(10)-triene-17-one.
Another problem in physiology of the fish ovary is its capacity for synthesizing 11-keto- and $11 \beta$ hydroxysteroids. 11-Ketotestosterone has a strong androgenic capacity (Idler et al., 1961), and therefore might be considered as a male sex hormone in fish. However, it has also been isolated from ovarian tissue (Eylath \& Eckstein, 1969); incubation experiments proved ovaries to be capable of synthesizing 11-ketotestosterone (Eckstein, 1970; Eckstein \& Eylath, 1970; Eckstein \& Katz, 1971; Reinboth, 1972), and in some cases 11 $\beta$-hydroxytestosterone (Eckstein and Katz, 1971; Reinboth, 1972). The synthesis of the mentioned steroids could not be demonstrated in ovaries of young guppies (Lambert et al., 1971). It is possible that in older animals the 11-hydroxylation is functioning. For this reason it has been attempted to demonstrate the formation of such steroids in ovaries of virgin guppies which are at least 12 months old.

\section{MATERIALS AND METHODS}

\section{Animals}

Virgin female guppies (Poecilia reticulata) were reared under laboratory conditions at $24^{\circ} \mathrm{C}$ and artificial light during 12 consecutive hours per day.

\section{Radioactive steroids}

The following radioactive steroids, all purchased from New England Nuclear Corp., Boston, Mas., U.S.A., 
were used following purification by thinlayer chromatography: pregnenolone- $7 \alpha^{3} \mathrm{H}$ (sp. act.: $17 \mathrm{Ci} / \mathrm{mMol}$ ), androstenedione-1,2- ${ }^{3} \mathrm{H}$ (sp. act.: $48 \mathrm{Ci} / \mathrm{mMol}$ ), progesterone-4-14 $\mathrm{C}$ (sp. act.: $57.3 \mathrm{mCi} / \mathrm{mMol}$ ), oestradiol$17 \beta-4-{ }^{14} \mathrm{C}$ (sp. act.: $52 \mathrm{mCi} / \mathrm{mMol}$ ), oestrone-4- ${ }^{14} \mathrm{C}$ (sp. act.: $45.2 \mathrm{mCi} / \mathrm{mMol}$ ), cortisone-4- ${ }^{14} \mathrm{C}$ (sp. act.: 55 $\mathrm{mCi} / \mathrm{mMol}$ ), cortisol-4-14 $\mathrm{C}$ (sp. act.: $55.1 \mathrm{mCi} / \mathrm{mMol}$ ).

$11 \beta$-Hydroxyandrostenedione-4- ${ }^{14} \mathrm{C}$ and adrenosterone-4-14 $\mathrm{C}$ were prepared from cortisol-4- ${ }^{14} \mathrm{C}$ and cortisone-4-14 $\mathrm{C}$ respectively by oxidation with sodium bismuthate. $11 \beta$-Hydroxytestosterone-4- ${ }^{14} \mathrm{C}$ and 11 ketotestosterone-4-14 $\mathrm{C}$ were then prepared from $11 \beta$ hydroxyandrostenedione-4- $-{ }^{14} \mathrm{C}$ and adrenosterone-4-14 $\mathrm{C}$ respectively by reduction with sodium borohydride.

\section{Reagents}

All chemicals used were of analytical grade; organic solvents were redistilled once just before use. Cofactors used in the incubation mixture were obtained from Boehringer, Mannheim, Germany.

\section{Chromatography}

Thin-layer chromatography (TLC) was carried out on precoated plates $(10 \times 20 \mathrm{~cm})$ with silica gel, F 254 (Merck, A.G.) or cellulose MN 300, F 254 (Antec, A.G.) in saturated tanks using the following systems: system 1: dichloromethane-methanol $(97: 3)$; system 2 : benzeneacetone $(8: 2)$; system 3 : benzene-methanol $(9: 1)$; system 4: benzene-cyclohexane $(1: 1)$; system 5 : benzene-ethylacetate $(7: 3)$; system 6 : hexaneethylacetate $(1: 1)$; system 7 : cyclohexane-ethylacetate $(1: 3)$; system 8: ethylacetate-cyclohexane-ethanol $(45$ : $45: 10)$; system $9:$ toluene-acetone $(7: 3)$; system 10 : petroleum ether $\left(40-60^{\circ} \mathrm{C}\right)$-tert. butanol $(1: 1)$; system 11: petroleum ether $\left(40-60^{\circ} \mathrm{C}\right)$-tert. butanol $(3: 1)$; system 12: toluene saturated with propylene glycol.

Only cellulose plates were developed in system 12 . The spotted cellulose plates were dipped up to the origin in a mixture of methanol-propylene glycol $(5: 1)$, and allowed to dry for $10 \mathrm{~min}$ before development. After chromatography, the 3-keto- $\Delta^{4}$-steroids were located by u.v. absorption, whereas the other steroids or derivates were detected by spraying with primuline according to Wright (1971).

Paper chromatography (PC) was carried out on Machery and Nagel M.N. $263 \mathrm{ff}$. paper (Düren, Germany) in the system petroleum ether $\left(40-60^{\circ} \mathrm{C}\right)$ methanol-water $(5: 4: 1)$. Steroids were detected by absorption of u.v. light.

Gas-liquid chromatography (GLC) was applied in the quantification of the steroids during the recrystallization procedure, by using a Hewlett-Packard 402 gas chromatograph with a flame ionization detector and a $4 \mathrm{ft}$ $3 \%$ SE 30 column.

\section{Microchemical reactions}

Oxidation was brought about with chromium trioxide according to Eckstein (1970).

Methylation was carried out with dimethyl sulphate as described by Brown et al. (1957).

Formylation was performed by dissolving the dry steroid in formic acid $98 \%(0.5 \mathrm{ml})$. After $2 \mathrm{hr}$ at room temperature the formylation is completed.
Saponification of steroid formates was carried out with sodium hydroxide according to Bush (1961).

\section{Measurement of radioactivity}

Samples were essayed using a Nuclear Chicago Mark I scintillation counter with a scintillator of PPO $(4 \mathrm{~g})$ and POPOP ( $40 \mathrm{mg}$ ) in toluene (11.). Radioactive areas on TLC plates and PC papers were located by means of a Berthold thin layer and paper radiogram scanner.

\section{Incubation procedure}

The ovaries were removed from decapitated guppies, pooled, weighed and homogenized at $0^{\circ} \mathrm{C}$ in a medium ( $1 \mathrm{ml} / 100 \mathrm{mg}$ tissue) containing per litre aqua dest.: $\mathrm{NaCl}(11.69 \mathrm{~g}), \mathrm{KCl}(0.37 \mathrm{~g}), \mathrm{CaCl}_{2}(0.44 \mathrm{~g}), \mathrm{MgCl}_{2}$ $(0.41 \mathrm{~g}), \mathrm{NaHCO}_{3}(0.08 \mathrm{~g}), \mathrm{KHCO}_{3}(0.14 \mathrm{~g})$, glucose $(0.10 \mathrm{~g})$, nicotinamide $(0.12 \mathrm{~g})$ and fumaric acid $(0.01 \mathrm{~g})$. Appropriate quantities of labeled precursors and cofactors (ATP, NAD, NADP, NADH and NADPH; $2 \mu \mathrm{Mol}$ of each) were prepared in $25 \mathrm{ml}$ incubation vials, to which the homogenates were added. Incubations were carried out at $25^{\circ} \mathrm{C}$ in an air atmosphere or in a $95 \%$ $\mathrm{O}_{2}$ and $5 \% \mathrm{CO}_{2}$ gas phase, with continuous shaking. After $1 \mathrm{hr}$, additional quantities $(2 \mu \mathrm{Mol})$ of cofactors were added and after a total of $2 \frac{1}{2}$ hr the enzyme reactions were terminated by the addition of dichloromethane $(10 \mathrm{ml})$.

\section{Extraction and fractionation}

Labeled and unlabeled carriers were added to the incubation mixture before extraction with dichloromethane $(3 \times 10 \mathrm{ml})$. The combined dichloromethane extracts were evaporated in vacuo and the residue dissolved in aqueous methanol $(70 \% ; 8 \mathrm{ml})$ and stored at $-18^{\circ} \mathrm{C}$ overnight to precipitate triglycerides. Following centrifugation the supernatant (the steroid fraction) was evaporated to dryness, and then fractionated into a phenolic and a neutral fraction (see Lambert et al., 1971).

\section{RESULTS}

\section{Incubation with pregnenolone- $7 \alpha^{-3} \mathrm{H}$ and Pro- gesterone-4- ${ }^{14} \mathrm{C}$ as precursors}

The homogenate of the ovaries $(190 \mathrm{mg})$ of eight, 4-month-old virgin guppies was incubated with ${ }^{3} \mathrm{H}$ pregnenolone $(4.99 \mu \mathrm{Ci} ; 10 \cdot 1 \mu \mathrm{g})$ and ${ }^{14}$-C-progesterone $(1.15 \mu \mathrm{Ci} ; 6.3 \mu \mathrm{g})$ in the presence of cofactors in an atmosphere of $95 \% \mathrm{O}_{2}$ and $5 \% \mathrm{CO}_{2}$. After the incubation the following steroids (100 $\mu \mathrm{g}$ of each) were added as carriers: pregnenolone, progesterone, $17 \alpha$-hydroxypregnenolone, $17 \alpha$-hydroxyprogesterone, dehydroepiandrosterone, androstenedione, testosterone, oestradiol and oestrone. Following the extraction and removal of triglycerides the steroid extract was fractionated into a phenolic fraction and a neutral fraction.

\section{Phenolic fraction}

Following TLC in system 3 the oestradiol and oestrone fractions were methylated. After TLC in system 8 it appeared that the ${ }^{3} \mathrm{H}$ as well as the ${ }^{14} \mathrm{C}$ 
activity, remaining in the methylated carriers of oestradiol and oestrone, were too low to permit further examination.

\section{Neutral fraction}

For a first separation the neutral fraction was subjected to PC. After developing, only the areas corresponding with the added carriers were eluted i.e. (1) 17 $\alpha$-hydroxypregnenolone, $17 \alpha$-hydroxyprogesterone and testosterone; (2) dehydroepiandrosterone; (3) androstenedione; (4) pregnenolone; (5) progesterone. TLC in system 2 of the first fraction effected a separation in a combined $17 \alpha-$ hydroxypregnenolone and testosterone fraction and in a 17 $\alpha$-hydroxyprogesterone fraction. After TLC in system 1, it was possible to separate $17 \alpha$-hydroxypregnenolone from testosterone. The individual steroid fractions were further purified by TLC, derivative formation and crystallization.

$17 \alpha$-Hydroxyprogesterone. The fraction containing the carrier $17 \alpha$-hydroxyprogesterone was subjected to the procedure of formylation. The ${ }^{9} \mathrm{H},{ }^{14} \mathrm{C}$ compound remained unaffected and showed an $R_{f}$ identical to authentic $17 \alpha$-hydroxyprogesterone after TLC in system 1 . Finally, the ${ }^{3} \mathrm{H},{ }^{14} \mathrm{C}$ compound showed a constant specific activity after repeated crystallizations (Table 1 ).

$17 \alpha$-Hydroxypregnenolone. The fraction was formylated and the radioactive material showed the same mobility on TLC in system 1 as authentic $17 \alpha$-hydroxypregnenolone formate. After saponification and a renewed TLC in the same system, the tritium active area appeared to correspond with carrier 17 $\alpha$-hydroxypregnenolone.

Dehydroepiandrosterone. The dehydroepiandrosterone fraction obtained after PC was separated into three radioactive areas after a TLC in system 1. One of these active areas corresponds with carrier dehydroepiandrosterone. Following a second TLC in system 7, the active dehydroepiandrosterone fraction was eluted and divided into three portions for oxidation, formylation and crystallization. After oxidation and formylation, and after TLC in system 1 the tritium active products showed an $R_{f}$ identical to androstenedione and dehydroepiandrosterone formate respectively. Moreover, a constant specific activity was reached after repeated crystallizations (Table 1).

Androstenedione. TLC in system 1 of the androstenedione fraction resulted in at least three radioactive areas, one of which corresponds with authentic androstenedione. The androstenedione area was eluted and the active compound appeared to resist oxidation and formylation. Finally, the substance showed a constant specific activity after repeated crystallizations (Table 1). The purified androstenedione was mainly tritium labeled; the ${ }^{8} \mathrm{H} /{ }^{14} \mathrm{C}$ ratio is 33 .

Testosterone. Formylation of the fraction containing the carrier testosterone yielded a compound with the same mobility as authentic testosterone formate after TLC in system 1. This formate was saponified, and after TLC in system 10 the radioactive product showed a similar chromatographic behaviour as authentic testosterone. After recrystallization to constant specific activity (Table 1), a ${ }^{3} \mathrm{H}$ activity was the only one to be detected.

\section{Incubation with androstenedione-1,2- ${ }^{8} \mathrm{H}$ as precursor}

Homogenized ovarian tissue $(400 \mathrm{mg}$ ) of six, $12-$ month-old virgin guppies was incubated with ${ }^{3} \mathrm{H}$ androstenedione $(6.7 \mu \mathrm{Ci})$ in the presence of cofactors in an air atmosphere. After incubation the following labeled carriers were added: $11 \beta$ hydroxytestosterone-4-14 $\mathrm{C}(8.93 \mathrm{nCi}, 50 \mu \mathrm{g}) ; 11$ ketotestosterone-4-14 $\mathrm{C}(7.63 \mathrm{nCi}, 50 \mu \mathrm{g}) ; 11 \beta$-hydroxyandrostenedione-4- ${ }^{14} \mathrm{C} \quad(7.89 \mathrm{nCi} ; \quad 50 \mu \mathrm{g})$; adrenosterone-4-14 $\mathrm{C}(6.21 \mathrm{nCi}, 50 \mu \mathrm{g})$; oestrone-4${ }^{14} \mathrm{C}(6.73 \mathrm{nCi}, 50 \mu \mathrm{g})$; oestradiol- $4{ }^{14} \mathrm{C}(8.04 \mathrm{nCi}$, $50 \mu \mathrm{g})$.

Following extraction and removal of triglycerides, the steroid extract was subjected to a phenolic separation procedure.

\section{Conversion to ${ }^{8} \mathrm{H}$-oestrogens}

The phenolic fractions could be separated with TLC in system 3 into two major radioactive areas corresponding with oestradiol and oestrone.

Table 1. The last three crystallizations of steroids isolated from an incubation of ovarian tissue of $P$. reticulata with pregnenolone- $-7 \alpha-{ }^{3} \mathrm{H}$ and progesterone $-4-{ }^{14} \mathrm{C}$

\begin{tabular}{llccc}
\hline & & \multicolumn{3}{c}{ Specific activity (dis/min per mg) } \\
\cline { 2 - 5 } \multicolumn{1}{c}{ Steroid } & & Crystallization 1 & Crystallization 2 & Crystallization 3 \\
\hline $17 \alpha$-Hydroxyprogesterone & ${ }^{3} \mathrm{H}$ & 4038 & 3304 & 3377 \\
& ${ }^{14} \mathrm{C}$ & 2603 & 2214 & 2282 \\
Dehydroepiandrosterone & ${ }^{3} \mathrm{H}$ & 2347 & 1830 & 1804 \\
& ${ }^{14} \mathrm{C}$ & - & - & - \\
Androstenedione & ${ }^{3} \mathrm{H}$ & 1478 & 1386 & 1391 \\
Testosterone & ${ }^{14} \mathrm{C}$ & 53 & 47 & 42 \\
& ${ }^{3} \mathrm{H}$ & 712 & 643 & 625 \\
\hline
\end{tabular}


Table 2. ${ }^{3} \mathrm{H} /{ }^{\mathbf{1 4}} \mathrm{C}$ ratios of steroids and their derivatives from an incubation of ovarian tissue of $P$. reticulata with androstenedione- $1,2-{ }^{3} \mathrm{H}$

\begin{tabular}{lcccc}
\hline \multicolumn{1}{c}{ Steroid } & \multicolumn{3}{c}{${ }^{3} \mathrm{H} /{ }^{14} \mathrm{C}$ ratios } \\
\cline { 2 - 5 } & Free & Formylated & Oxidized & Methylated \\
\hline Oestradiol & 7.98 & 7.83 & & 7.61 \\
11 $\beta$-Hydroxytestosterone & 0.66 & 0.57 & 0.55 & \\
11-Ketotestosterone & 2.13 & 1.96 & 2.04 & \\
\hline
\end{tabular}

Oestradiol. Part of the ${ }^{3} \mathrm{H}-{ }^{14} \mathrm{C}$ material, behaving chromatographically like oestradiol, was methylated. On TLC in system 6 the ${ }^{3} \mathrm{H}-{ }^{14} \mathrm{C}$ product had the same mobility as authentic oestradiol monomethyl ether. Another portion of the "oestradiol" fraction was formylated and after TLC in system 5 the ${ }^{3} \mathrm{H}-{ }^{14} \mathrm{C}$ product showed an $R_{f}$ value identical to authentic oestradiol diformate. The ${ }^{3} \mathrm{H} /{ }^{14} \mathrm{C}$ ratios of the two derivatives appeared to correspond (Table 2), and from the average of these ratios the total production was calculated. The percentage of androstenedione converted to oestradiol $( \pm 0.2 \% / 100 \mathrm{mg}$ tissue) was 0.9 .

Oestrone. The "oestrone" fraction was also partly formylated and partly methylated. The radioactivity in the areas corresponding with the derivatives after TLC in system 3 (oestrone formate) and in system 6 (oestrone-methyl ether) appeared to consist mainly of ${ }^{14} \mathrm{C}$ activity. The amount of ${ }^{3} \mathrm{H}-$ oestrone was too low to allow further examination.

\section{Conversion to $11 \beta$-hydroxy-and 11-ketosteroids}

The neutral fraction was first subjected to TLC in system 4 in order to remove fatty material, and then separated into four fractions by TLC in system 1. The four fractions, corresponding with the four added labeled carriers, were eluted and further purified as follows.

$11 \beta$-hydroxytestosterone. The fraction was purified first by TLC in system 9 (running twice) and then by TLC on cellulose plates in system 12 . The ${ }^{3} \mathrm{H},{ }^{14} \mathrm{C}$ material, corresponding in $R_{f}$ value with authentic $11 \beta$-hydroxytestosterone, was then partly oxidized. After TLC in system 1 , the ${ }^{3} \mathrm{H},{ }^{14} \mathrm{C}$ product had the same mobility as authentic $11 \beta$-hydroxyandrostenedione. Another portion was formylated and after TLC in system 1 the chromatographic behaviour was the same as authentic $11 \beta$-hydroxytestosterone formate. From the free steroid and both derivatives, the ${ }^{8} \mathrm{H} /{ }^{14} \mathrm{C}$ ratios were established (Table 2); from the average of the ratios it was calculated that \pm 0.02 per cent of androstenedione was converted to $11 \beta$-hydroxytestosterone.

11-Ketotestosterone. This fraction was chromatographed first by TLC in system 10 and then by partition chromatography on cellulose plates (system 12). Oxidation of the ${ }^{3} \mathrm{H},{ }^{14} \mathrm{C}$ material, eluted after partition chromatography, yielded a ${ }^{3} \mathrm{H},{ }^{14} \mathrm{C}$ com- pound with the same mobility as authentic adrenosterone on TLC in system 1. Formylation of the above-mentioned ${ }^{3} \mathrm{H},{ }^{14} \mathrm{C}$ material and subsequent TLC in system 1 showed a ${ }^{3} \mathrm{H},{ }^{14} \mathrm{C}$ product with an $R_{f}$ identical to that of authentic 11-ketotestosterone formate. From the ${ }^{3} \mathrm{H} /{ }^{14} \mathrm{C}$ ratios (Table 2) the total amount of produced 11-ketotestosterone was calculated; 0.2 per cent of androstenedione was converted to 11-ketotestosterone.

$11 \beta$-Hydroxyandrostenedione, adrenosterone. These fractions were purified by TLC in system 11 . A second chromatography was carried out on cellulose plates in system 12. After these two purification steps, the levels of ${ }^{3} \mathrm{H}$ activity remaining with each steroid appeared to be too low to permit further examination.

\section{DISCUSSION}

In the ovary of the guppy, $P$. reticulata, steroidogenesis takes place in the granulosa cells of growing follicles (Lambert, 1970; Lambert \& van Oordt, 1974). Two different incubation experiments were carried out to investigate some pathways in steroidogenesis. Firstly, homogenized ovarian tissue of 3 -month-old virgin guppies was incubated with ${ }^{3} \mathrm{H}$-pregnenolone and ${ }^{14} \mathrm{C}$-progesterone, to study which metabolic pathway is functioning the delta- 5 route, or the delta- 4 route. A second incubation was carried out with ovarian homogenates of 12 -month-old virgin guppies, with ${ }^{3} \mathrm{H}$-androstenedione as the precursor, to determine whether the ovary is able to synthesize steroids with functional groups in the 11-position.

The results of the ${ }^{3} \mathrm{H}$-pregnenolone and ${ }^{14} \mathrm{C}$ progesterone incubation demonstrate that the ovary of young guppies contains enzyme systems for synthesizing steroids by the delta-5 as well as the delta-4 pathway. The synthesis by the delta-5 route follows from the isolation of tritiated dehydroepiandrosterone. The isolation of ${ }^{14} \mathrm{C}$-labeled androstenedione indicates the possibility of synthesizing steroids by the delta- 4 route. The delta- 4 route does not seem to be the principal pathway in the ovary of the guppy, for the amount of ${ }^{14} \mathrm{C}$ androstenedione is low in comparison with the amount of ${ }^{3} \mathrm{H}$-androstenedione (the ${ }^{3} \mathrm{H} /{ }^{14} \mathrm{C}$ ratio is 33). Moreover, in the testosterone fraction, tritium activity was the only one to be detected. 
From the differences of the ${ }^{3} \mathrm{H} /{ }^{14} \mathrm{C}$ ratios of $17 \alpha$ hydroxyprogesterone $\left({ }^{3} \mathrm{H} /{ }^{14} \mathrm{C}: 1 \cdot 5\right)$, and androstenedione $\left({ }^{3} \mathrm{H} /{ }^{14} \mathrm{C}: 33\right)$ it may be concluded that conversion of $17 \alpha$-hydroxyprogesterone to androstenedione seems to be the rate-limiting step. Thus, in the ovary of the guppy, steroidogenesis mainly operates by the delta-5 pathway. Eckstein (1970) postulated that in the ovary of Tilapia aurea, steroidogenesis may take place via three different routes, i.e. a presumably predominating delta-5 route, the delta- 4 route and a third route, where progesterone may be converted to testosterone without androstendione as an intermediate. In the guppy, there are no indications for this third pathway. Although we have not succeeded in demonstrating a synthesis of oestradiol in this experiment, it may be concluded that ovaries of 3-month-old guppies should be able to synthesize oestradiol with pregnenolone as precursor, since it not only transforms the latter into androstenedione but it is also able to convert androstenedione to oestradiol (Lambert et al., 1971).

The results of the androstenedione incubation seem to prove that the ovaries of old guppies are capable of synthesizing 11/-hydroxy- and 11-ketosteroids; tritiated 11 $\beta$-hydroxytestosterone as well as tritiated 11-ketotestosterone have been isolated. A synthesis of $11 \beta$-hydroxy-androstenedione and adrenosteron, however, has not been demonstrated. Although an interpretation of quantitative findings of in vitro studies is difficult, the obvious predominance of 11-ketotestosterone indicates that it is the most important one from all steroids with a functional group in the 11-position synthesized in the ovaries of 12-month-old guppies. A transformation of androstenedione to oestradiol by homogenates of the ovaries from older guppies was also established; per $100 \mathrm{mg}$ of ovarian tissue 0.2 per cent of androstenedione appeared to be converted to oestradiol. The recent results obtained with ovaries of 12-month-old guppies are different from the results of the androstenedione incubation with homogenates of ovaries from 3-month-old animals (Lambert et al., 1971). None of the abovementioned steroids with a functional group in the 11-position has been demonstrated after incubation of young ovaries with ${ }^{3} \mathrm{H}$-androstenedione; the conversion of androstenedione into oestradiol was as high as $0.5 \%$ per $100 \mathrm{mg}$ tissue. These differences seem to prove that steroid metabolism in the ovary changes during aging of virgin guppies. Oestrogen synthesis (oestradiol) decreases, whereas androgen synthesis (11-ketotestosterone) increases. The production of typical fish androgens, such as 11ketotestosterone and $11 \beta$-hydroxytestosterone, in the ovaries of old guppies might be the explanation of sex conversion, occasionally observed in older female guppies.

Acknowledgement-The authors are grateful to Professor Dr. P. G. W. J. van Oordt for his interest and his critical reading of the manuscript.

\section{REFERENCES}

Axelrod L. R., Matthiussen C., Goldzieher J. W. \& Pulliam J. E. (1965) Definitive identification of microquantities of radioactive steroids by recrystallization to constant specific activity. Acta. Endoc., Copenh. 49, (Suppl. 99).

Brown J. B., Bulbrook R. D. \& Greenwood F. C. (1957) An additional purification step for a method for estimating oestriol, oestrone and oestradiol in human urine. J. Endocr. 16, 49-56.

BusH I. E. (1961) The Chromatography of Steroids. Pergamon Press, Oxford.

ECKSTEIN B. (1970) Metabolic pathways of steroid biosynthesis in ovarian tissue of a teleost, Tilapia aurea. Gen. \& compar. Endocr, 14, 303-312.

ECKSTEIN B. \& EyLATH U. (1970) The occurrence and biosynthesis in vitro of 11-ketotestosterone in ovarian tissue of the mullet, Mugil capito, derived from two biotopes. Gen. \& compar. Endocr. 14, 396-403.

ECKSTEIN B. \& KaTZ Y. (1971) Steroidogenesis in postand prespawned ovaries of a Cichlid fish, Tilapia aurea. Comp. Biochem. Physiol. 38A, 329-338.

Eylath U. \& Eckstein B. (1969) Steroid biosynthesis in vitro by ovarian tissue of mullets (Mugil sp.) from sea and fresh-water. Gen. \& compar. Endocr. 13, 504.

IDLER D. R., SCHMIDT P. J. \& BIELY J. (1961) The androgenic activity of 11-ketotestosterone: a steroid in salmon plasma. Can. J. Biochem. Physiol. 39, 317320.

LAmbert J. G. D. (1970) The ovary of the guppy Poecilia reticulata. The granulosa cells as sites of steroid biosynthesis. Gen. \& compar. Endocr. 15, 464-476.

LAMbert J. G. D., Thiussen J. H. H. \& ExLATH U. (1971) Conversion of ${ }^{3} \mathrm{H}$-androstenedione and ${ }^{3} \mathrm{H}$-testosterone to ${ }^{3} \mathrm{H}$-oestradiol-17 $\beta$ in vitro by the ovary of the guppy Poecilia reticulata. Proc. Kon. Ned. Akad. Wet. Ser. C. 74, 52-59.

LAmbert J. G. D. \& van OORDT P. G. W. J. (1974) Ovarian hormones in teleosts. Fortshritte der Zoologie. 22, 340-349.

REINBOTH R. (1972) Hormonal control of the teleost ovary. Am. Zoologist 12, 307-324.

WrIGHT R. S. (1971) A reagent for the non-destructive location of steroids and some other lipophilic materials on silica gel thin-layer chromatograms. J. Chromatogr. $59,220-221$.

Key Word Index-Teleost; ovary; steroidogenesis; Poecilia reticulata. 